\title{
Social cognitive and later language acquisition
}

\author{
Silke Brandt \\ Lancaster University \& ESRC International Centre for Language and \\ Communicative Development
}

\section{Preface}

My first contact with language acquisition research and Elena was as a HiWi (student assistant in Germany) at the Max Planck Institute for Evolutionary Anthropology in Leipzig. Together with other students from the University of Leipzig, I was transcribing and coding child-caregiver interactions in German, which were mainly about trains (der Rasende Roland) and some old German buildings (die Frauenkirche in Dresden). These interactions are now publicly available in the Leo corpus on CHILDES (MacWhinney, 2000). Our open-plan HiWi office was situated right between Elena's and Mike Tomasello's offices. They usually had their doors open and did not get up from their desks to talk to teach other. What all of us HiWi's were soon impressed by was Elena's strong and loud voice, which led us to call her The Voice.

Later, as a PhD student, I've learned that Elena also uses her strong and loud voice to ask questions without a microphone after conference talks. And I've learned that Elena uses her voice to support early career researchers. At the Max Planck Institute, we could really see that both Elena and Mike were much more interested in what questions and ideas people were asking and developing than in who was asking those questions or developing those ideas (an established professor or a student intern). Finally, I've also learned that Elena herself never stops using her voice to ask new, interesting, open minded, and theoretically important questions about child language acquisition.

\section{Language acquisition and Theory of Mind in interaction}

In order to communicate successfully, children - and adults - have to understand that their interlocutors can have attitudes, perspectives, beliefs, and knowledge states that differ from their own. One of the most commonly used tasks to test children's understanding of other people's beliefs and knowledge states is the Change of Location test, where a story character has a false belief (Wimmer \& Perner, 1983). In this false belief test, children typically hear and see the following kind of story:

"Maxi puts his marble into a basket. Then he goes out to play in the park. While he is out to play, his sister Sally takes the marble out of the basket and puts it into a box. Then Sally also goes out to play. When Maxi comes back from the park, he wants to play with his marble".

After the story children get asked the crucial test question:

"Where will Maxi look for his marble - in the basket or in the box?" 
In order to make sure that children have followed the story, they also get asked two control questions:

"Where is the marble really now?"

"And where did Maxi put the marble in the beginning?"

At around the age of four years, children typically start to give the correct answer to the test question (Wellman, Cross, \& Watson, 2001). In order to give the right answer, children have to be able to distinguish between the character's false belief (i.e. that the marble is still in the basket) and their own knowledge of the actual location of the marble (i.e. that the marble is really in the box now). They also have to inhibit an egocentric response, which would be based on their own representation of the situation (i.e. that they would look in the box because that's the current location of the marble).

Interestingly, deaf children who grow up with hearing parents and thus have no access to a sign language at home are delayed in their understanding of false belief. Importantly, however, deaf children who grow up with deaf parents and are exposed to a sign language from early on develop an understanding of false belief on the same time scale as hearing children growing up with hearing parents and a spoken language (Schick, de Villiers, de Villiers, \& Hoffmeister, 2007).

In addition, there is some evidence suggesting that even adults who have not acquired a fully developed language can struggle with false belief tests. Pyers and Senghas (2009) investigated false belief understanding in adults and adolescents who have developed Nicaraguan Sign Language. This sign language has only started to develop in the late 1970's when deaf children in Nicaragua first came together in a newly established school for the deaf. Before this school had been established, these children did not have much contact with other deaf individuals and were mainly communicating with their hearing caregivers by using home signs. Even though home signs share some features with fully developed sign languages and spoken languages, they also lack a number of grammatical and semantic features (e.g., Senghas \& Coppola, 2001). When these home signers came together in the new school, children in the first cohort started to develop a simple version of Nicaraguan Sign Language. Children in the second cohort learned this developing sign language from the first cohort and developed it further into a more complex language with more grammatical and semantic features. Children from both the first and second cohorts are adults now. When first tested on their linguistic skills and false belief understanding in 2001, adults and adolescents from the second cohort produced significantly more mental verbs (e.g., know, think) than the first cohort. Adults and adolescents from the second cohort also outperformed the first cohort on a low-verbal version of the Change of Location false belief test described above. On average, adults from the first cohort passed fewer than one out of four false belief tests, whereas most individuals from the second cohort passed all four.

Taken together, these data from deaf children as well as adults and adolescents can be taken as clear evidence that having access to a fully developed sign language supports the understanding of others' beliefs. Similarly, a large number of studies with hearing children have found strong relationships between children's linguistic skills and their false belief understanding, and most of them suggest that language precedes false belief (see meta analyses by Farrar, Benigno, Tompkins, and Gage, 2017; Milligan, Astington, \& Dack, 2007). 


\section{Interactions between syntax, verbal semantics and false belief}

However, it is far from clear how exactly language supports false belief. Some researchers suggest that just taking part in everyday conversation makes children aware of the fact that people can differ in their beliefs, knowledge states, attitudes, and perspectives (e.g., Harris, de Rosnay, \& Pons, 2005). For example, the use of alternative labels (e.g., rabbit vs. bunny; coast vs. shore; aunt vs. mother) already points to different perspectives on and mental representations of the same object, scene, or person. In accordance with this approach, Perner, Stummer, Sprung, and Doherty (2002) could show that children's increasing ability to produce and comprehend alternative labels developed in parallel with their increasing understanding of false belief. Similarly, Lohmann and Tomasello (2003) found in their training study that simply talking about deceptive objects, such as candles looking like apples, promotes children's false belief understanding. That is, children who experienced these deceptive objects together with utterances such as "right, it really is a candle" improved in their false belief understanding. On the other hand, children who only heard minimal language (e.g., "and now look") did not show any advances in their understanding of others' beliefs. In another training study, Lu, Su, and Wang (2008) were able to show that encouraging children to just talk about other people's actions can also lead to improved false belief understanding. As stated by Harris et al. (2005, p. 72), any linguistic expression that points to individual and others' perspectives promotes Theory of Mind. The assumption that an exposure to general language promotes children's false belief understanding is further supported by a great number of studies finding correlations and longitudinal links between children' performance on standardized tests of grammar and vocabulary and their false belief understanding (e.g., Cheung et al., 2004; Farrar \& Maag, 2002; Tardif, So, \& Kaciroti, 2007).

Others, however, argue that it is caregivers' use of specific mental verbs, such as think and know, that points children to different beliefs and knowledge states. For example, Ruffman, Slade, and Crowe (2002) found that the frequency of mental state verbs in mothers' language was positively correlated with their children's false belief understanding later on.

Yet another suggestion is that learning complex syntactic structures provides children with a tool that allows them to represent different beliefs (e.g., Astington \& Jenkins, 1999). Related to this last point, de Villiers and colleagues (e.g., de Villiers \& Pyers, 2002) have argued that only specific syntactic structures, namely complement clause structures, allow children to represent and develop an understanding of false belief. More precisely, complement clause structures (e.g., "I know that the marble is in the box now" and "Maxi thinks that the marble is still in the basket") allow us to talk about and represent the same situation from different mental perspectives - in an explicit and flexible manner.

Teasing apart the different linguistic factors can be difficult. For example, mental verbs and complement clause constructions are used and processed in and cannot be taken out of everyday conversation. Similarly, mental verbs like know and think are often used in complement clause structures (e.g., "Maxi thinks that the marble is still in the basket"). There is some evidence, however, that complement clause constructions are also positively related to children's false belief understanding when they are used without mental verbs. That is, children's understanding of complement clause constructions with communication verbs (e.g., "Maxi said that the 
marble is still in the basket") also predicts their false belief understanding (e.g., de Villiers \& Pyers, 2002; Lohmann \& Tomasello, 2003). This led de Villiers and Pyers (2002) to argue that it is the syntax, not the semantics, of complement clause constructions that promotes children's false belief development.

However, when turning to languages that allow an even greater variety of verb types to be used in complement clause structures, the pictures looks a bit different. In German, for example, it is also common and grammatical to use desire verbs together with finite complement clauses:

Maxi will, dass die Murmel in dem Korb ist. Maxi wants that the marble in the basket is.

'Maxi wants the marble to be in the basket'

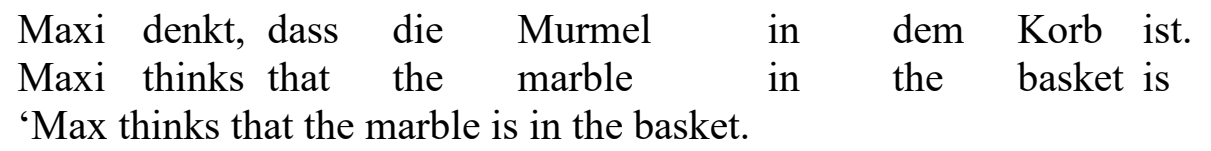

When Perner, Sprung, Zauner, and Haider (2003) looked at German-speaking children's comprehension of complement clause structures used with different kinds of verbs, they found that children understood complement clause structures with desire verbs like will 'want' (see example (1)) before they understood the same clause types with communication and mental verbs like denken 'think' (see example (2)). In addition, children's understanding of complement clause structures with desire verbs was not related to their understanding of false belief.

This led de Villiers (2005) to refine her hypothesis and suggest that it is only realis complements that allow children to acquire an understanding of false belief. The crucial feature of a realis complement, such as (2) above, is that they refer to a mental representations of a situation in the past or present (e.g., that the marble is or was in the basket). This mental representation can be true or false. In this example, the marble could or could not be in the basket. When used with desire verbs like want, however, complements are irrealis. They refer to representations of future or hypothetical events. The superordinate proposition (e.g., "Maxi wants") does not occur at the same time as the subordinate proposition ("that the marble be in the basket").

This research suggests that we might not be able to disentangle the semantic and syntactic features of complement clause constructions as both seem to play a crucial role in supporting children's ability to learn and understand false belief. Another line of research suggests that we should also consider multiple linguistic routes to false belief. As mentioned above, several training and longitudinal studies have found that children's understanding of and their exposure to complement clause structures predicts and facilitates their understanding of false belief (e.g., de Villiers \& Pyers, 2002; Lohmann \& Tomasello, 2003). However, Lohmann and Tomasello (2003) also found that exposing children to simple language also leads to better false belief understanding later on. Interestingly, the results from a recent meta analysis and qualitative review suggest that there might also be differences between typically developing children and children with autism when it comes to choosing which linguistic route best supports false belief. Farrar and colleagues (2017) suggest that typically developing children might actually rely most on their general linguistic 
skills, including simple language, whereas children with autism mostly benefit from acquiring the complex structure of complement clauses.

Interactions between syntax, verbal semantics and false belief from a cross-linguistic perspective

What I will discuss in more detail in the remainder of this chapter is that the choice of linguistic route to false belief can also be affected by cross-linguistic differences. In particular, I will argue that how different types of complement clauses facilitate children's false belief understanding depends on how these syntactic constructions are used in a given language. As summarized above, de Villiers (2005) suggested that, in languages such as English and German, complement clauses only support children's false belief development when they are of the realis type. Realis complement clauses can be used together with communication and mental verbs like say, think and know, but not with desire verbs like want.

For Chinese, however, Cheung, Chen, and Yeung (2009) proposed another type of modification. Unlike English and German, both Cantonese and Mandarin Chinese have a mental verb that explicitly encodes false belief. The Cantonese verb ji5wai4 (yi3wei2 in Mandarin) can be translated as 'falsely think'. When Cheung et al. (2009) tested Cantonese children's understanding of complement clause constructions and how they are related to false belief, they found that only the understanding of complement clauses used together with this explicit false belief verb was positively correlated with children's false belief understanding. Cantonese children's understanding of complement clauses used together with communication or neutral mental verbs (e.g., 'say' or 'think') played no unique role in predicting children's false belief understanding. In other words, the link between false belief and complement clause structures interacts with the realis vs. irrealis distinction in English and German, with only realis complement clauses showing a positive relation to false belief (e.g., de Villiers, 2005). In Cantonese Chinese, however, the positive relation between false belief and complement clause structures interacts with the distinction between explicit false belief verbs vs. any other mental or communication verb used in the complement clause construction.

In a recent study, we were able to replicate this finding for Mandarin and Cantonese Chinese using different linguistic tasks than the ones used by Cheung et al. (2009) (Brandt, Li, \& Chan, in prep.). Unlike Cheung et al. (2009), who used different tasks for complement clause constructions with 'falsely think' and complement clause constructions with other mental and communication verbs, we tested the understanding of complement clause constructions with different verb types within the same task. We used the hidden object task by Moore, Bryant, and Furrow (1989), where children hear contrastive statements, such as: "I think that the sticker is in the blue box" vs. "I know that the sticker is in the red box". In order to pass this task, children need to understand that the proposition marked by know is more trustworthy than the proposition marked by think. When testing Chinese children, we contrasted 'know' vs. 'think' and 'know' vs. 'falsely think'. We found that Chinese children's performance in this hidden object task also correlate with their false belief understanding. However, regression analyses suggest that it is only the contrast between 'know' vs. 'falsely think' that is uniquely related to false belief (see Brandt, et al., submitted). 


\section{Looking at usage patterns and functions across languages}

Turning back to English and German, several studies suggest that not just the choice of a specific verb type, but also the choice of a specific subject type can lead to differences in children's interpretation of complement clause constructions and how they are related to their false belief understanding. As shown by Brandt, Buttelmann, Lieven, and Tomasello (2016), English-speaking children understand complement clause construction with third person subjects in the main clause (e.g., "he knows that the sticker is in the blue box") better than complement clause constructions with first person subjects in the main clause (e.g., "I know that the sticker is in the blue box"). To save some words, I will refer to these two constructions as third and first person complements from here on. Brandt et al. (2016) also found that children's understanding of third person complements was more strongly related to their false belief understanding than their understanding of first person complements (for similar results in English see Howard Gola, 2012). Similar patterns were found for Germanspeaking 3- and 4-year-olds (Brandt \& Buttelmann, 2015).

We have recently replicated this finding in a more carefully designed longitudinal study with English-speaking 3-year-olds, where we also tested and controlled for children's general linguistic skills and a number of additional individual difference measures (Boeg Thomsen, Theakston, Kandemirci, \& Brandt, in prep.). As has been shown for general linguistic skills (e.g., Cheung et al., 2004; Farrar \& Maag, 2002), children's executive functioning skills also seem to be positively related to false belief understanding (e.g., Carlson, Moses, \& Breton, 2002). As shortly mentioned before, children have to inhibit their own knowledge state and their access to reality when answering the test question in a false belief test. And since they have to remember the story, their general memory skills might also affect their performance in these Theory of Mind tests (e.g., Davis \& Pratt, 1995). Therefore, when children first came into the lab for this longitudinal study around the age of three years, we did not just test their understanding of complement clause constructions, we also assessed their understanding of vocabulary and grammar, their inhibitory control, as well as their short term and working memory. Another methodological improvement in this longitudinal study was that we avoided using any complement clause constructions in the false belief test questions. In previous longitudinal studies, some of the false belief test questions contained the same linguistic structures and verbs as the ones used for testing children's understanding of complement clauses. For example, de Villiers and Pyers (2002) used sentences like "what did she think she bought" when testing children on their understanding of complement clause structures. And they used highly similar sentences like "what did you think was in the box" when testing their understanding of false belief. It is thus not clear whether children's performance in the false belief test was measured independently of their understanding of complement clause constructions. In our study we changed the sentences used in the false belief tasks to simple sentences, such as "what did you first think about this box"? And "did you think about raisins or a ball first"?

What we were mainly interested in was which of the linguistic and cognitive skills we measured around the age of three predicted children's false belief understanding half a year later. Confirming results from the correlational study (Brandt et al., 2016), we found that the best predictors were children's understanding of complement clauses and that third person complements showed a stronger relation 
to false belief than first person complements. To summarize, the relationship between complement clauses and false belief holds even when we apply strict controls. However, in languages like English and German, the link between complement clauses and false belief is moderated by an interaction with subject type.

The question is whether we can explain this difference between first and third person complements and their relation to false belief based on de Villiers' (2005) semantic distinction between realis and irrealis complements or whether we need to turn to an alternative explanation. In other words, would it be possible that the subject changes the semantics of mental verbs? De Villiers (2005, p. 213) does not discuss this issue. When she discusses the distinction between realis complements with verbs like think and irrealis complements with verbs like want, she states that this distinction is "carried by the nature of the verb". However, it is noticeable that all of de Villiers' examples are third person complements. Moreover, the training and longitudinal studies that found relations between complement clauses and false belief have either used third person complements only or a mix of second and third person complements. For example, in the study by Lohmann and Tomasello (2003, p. 1144), children in the complements training group heard sentences like the following:

(3) What do you think this is?

(4) Do you think you can light this candle?

(5) Does Ernie know that candles can be dangerous?

Sentences like these all qualify as realis complements: they refer to mental representations of objects in the here and now that may or may not correspond to the real nature of these objects ${ }^{1}$. But the same can be said about first person complements:

(3a) I think this is a candle.

(4a) I think that you can light this candle.

In German, these first person complements could also be turned into irrealis complements by just changing the verb. In English, this change would also lead to an infinite complement. The irrealis complement below does not refer to a mental representation of an object observable at the time of speaking.

(3b) I want this to be a candle.

To summarize, both first and third person complements can be realis or irrealis, depending on which verb types are used. Whether they are used with first or third person subjects has no effect on the semantics of these mental verbs.

If we want to explain the difference between children's understanding of first and third person complements and their relation to false belief, we need to turn to corpus data to see how these syntactic constructions are used in actual discourse outside the lab. When Thompson (2002) investigated how American-English adults use the most frequent complement-taking verbs (i.e., think, guess, remember, know, see), she found that in the vast majority of instances they used them together with a first person subject (e.g., "I guess he's OK"). Based on this frequency distribution, she argued that complement-taking phrases like I guess or I think can be considered

\footnotetext{
${ }^{1}$ Note that only some of the complements these studies contained modal verbs like can, which might not easily be judged as true or false.
} 
fixed formulas or chunks. When she had a closer look at the discourse function of these fixed formulas, she suggested that most of them function as epistemic markers, which express speaker certainty towards a proposition. For example, when saying "I think the sticker is in the red box", the speaker expresses that they are not completely certain whether or not "the sticker is in the red box". If they were completely certain, they would say "I know the sticker is in the red box" or just "the sticker is in the red box".

Thompson (2002) also suggested that complement clause constructions that contain these formulaic epistemic markers do not have the same subordinate structure as complement clause constructions used with less frequent third person complementtaking phrases, such as "the boy thought". In a prototypical subordinate structure, the main clause contains the foreground information and the subordinate clause contains background information. For example, in an utterance such as "the boy thought the sticker was in the red box", the focus is typically on the thinking process. However, when you look at how first person complements are treated in conversation, speakers typically focus on what is expressed in the subordinate complement clause. This is nicely shown in this example (Thompson, 2002, p. 132):

(6) (talking about a photo collage on the wall)

Terry: I think it's cool.

Abbie: $\quad$ It is cool.

Maureen: $\quad$ It is great.

Here, the focus is clearly not on the thinking process, but on what is expressed in the complement clause "it's cool". Similar patterns in terms of frequency and discourse function of first versus third person complements have been observed in Dutch adult conversation (Verhagen, 2005) and, most importantly, also in the speech addressed to children learning German and English (Brandt, Lieven, and Tomasello, 2010; Diessel, 2004).

Looking at children's interpretation of complement clauses, children also tend to focus on the proposition expressed by the subordinate complement clause. As has been argued by Lewis, Hacquard, and Lidz (2017), children interpret these complex structures according to how they are most often used in child-directed speech. When they are asked, for example, whether a sentence like "Dora thinks that Swiper is behind the curtain" is correct in a scenario where the belief is false (because Swiper is not behind the curtain) they usually tend to say "no". However, Lewis and colleagues (2017) could also show that children around the age four years are able to focus on the belief and judge this sentence as correct when the belief aspect is made more prominent by, for example, introducing a second character with a different belief.

When we look at children's own production of complement clause constructions in spontaneous speech, it is striking that they start producing these syntactic structures around the age of three years (e.g., Diessel, 2004), which is much earlier than the age at which they typically show an understanding of false belief (at around 4 years). However, as has been shown for other syntactic constructions (e.g., Bannard, Lieven, \& Tomasello, 2009; Theakston \& Lieven, 2017), children's first complement clause constructions are mostly made up of formulaic chunks. That is, the vast majority of children's early complement clause constructions are first person complements. And it has been argued that, just as in adult speech, these syntactic constructions can be analyzed as a formulaic epistemic marker used together with a simple proposition (Brandt et al., 2010; Diessel, 2004). In other words, most of the 
first person complements that children and adults use in spontaneous speech do not have the same function and subordinate structure as the third person complements typically used in experimental studies looking at children's understanding of complement clause structures and false belief. Whereas complement-taking phrases with first person subjects (e.g., "I think") mainly function as epistemic markers, complement-taking phrases with third person subjects (e.g., "he thinks") refer to a person's mental process (thinking) and a mental representation ("that the sticker is in the red box"). This would also explain why we find that third person subjects are more closely related to children's developing understanding of false belief (e.g., Brandt et al., 2016).

The last question I would like to investigate is whether the different functions of first and third person complements and their different relations to false belief are universal or whether they are affected by the way they are used in spoken discourse. Thompson (2002) suggests that there is a link between the frequent use and the epistemic function of first person complements. As has been shown for other lexical items and constructions, frequently used phrases often turn into chunks that cannot be analyzed in terms of their component parts anymore. This is also evident in discourse markers like "you know" in utterances like "this is great, you know". When these discourse markers are used and encountered in conversation, people would rarely respond with "no I didn't know that".

The best test case for investigating the link between the frequent use and epistemic function of first person complement-taking phrases would be a language where mental verbs are not frequently or predominantly used with first person subjects. We found this to be the case in Chinese (Brandt et al., submitted). When we looked at Mandarin Chinese caregivers' use of mental verbs in complement clause constructions, there were two important findings: First of all, the number of mental verbs used in Mandarin is very low compared to English and German (see also Tardif \& Wellman, 2000). Secondly, Mandarin Chinese caregivers do not show a first person bias. That is, whereas English and German-speaking caregivers overwhelmingly use mental verbs with first person subjects, Mandarin Chinese caregivers use mental verbs with different kinds of subjects. For example, the frequent mental verbs jue2de2 'think' and zhildao4 'know' are most frequently used with second person singular subjects (58\% and 54\% respectively), followed by first person singular subjects (34\% and $37 \%$ ) and third person singular subjects (4\% and 5\%). These corpus data suggest that Mandarin Chinese speakers are less likely to operate with fixed formulas like 'I think' or 'I guess' when they use complement clause constructions. If this is the case, we should also expect smaller or no differences between first and third person complements and their relation to false belief in Chinese.

In order to investigate this, we replicated the study by Brandt et al. (2016) with Mandarin Chinese children (see Brandt et al., submitted). As a reminder, in this study children first did the hidden object task (Moore et al., 1989), where they heard contrastive statements (e.g., 'I know that the sticker is in the blue box' vs. 'I think that the sticker is in the red box'). These statements were presented as first or third person complements (i.e., 'I know...' vs. 'I think...' or 'he knows...' vs. 'he thinks...'). As reported above, we also used the explicit false belief verb ji5wai4 'falsely think' in half of the trials. After the hidden object task, children took part in four standard false belief tasks.

We found that, as in English and German, children were better at interpreting third person complements than first person complements. Unlike in English and German, however, when we looked at the link between children's understanding of 
complement clauses and their understanding of false belief, we did not find a significant difference between first and third person complements. That is, when used with neutral verbs like 'think', neither first nor third person complements played a unique role in children's false belief understanding. When used with the explicit verb ji5wai4 'falsely think', both first and third person complements were related to false belief.

The finding that, just like English- and German-speaking children, Chinese children also showed a better understanding of third person complements was somewhat surprising. We have suggested that this might be due to task effects rather than linguistic usage patterns. For example, when hearing 'I think' and 'I know' children might need to switch perspective in order to solve the task: I should follow the puppet's advice who said that 'he knew'. This is not the case for third person complements where children hear 'he thinks' and 'he knows'. In addition, hearing 'he knows' also means that the producer of these utterances endorses the puppet who 'knows'. That is, we would not say "he knows that the sticker is in the red box" if we had some reason to belief that the sticker was not in the red box. This might explain why both English and Chinese children find it easier to interpret third person complements - despite different usage patterns in spontaneous speech.

Our corpus data suggest that Chinese speakers are less likely to represent first person complement-taking phrases as unanalyzed chunks or discourse markers, where the meaning of the mental verbs is not in focus anymore. The fact that we found no difference in how first and third person complements are related to Chinese children's false belief understanding suggests that this is indeed the case. Usage patterns can affect the function of different types of complement clauses. And since there is more equivalence in Mandarin Chinese, both first and third person complements are related to false belief.

\section{Summary and Conclusion}

Previous research already suggested that it is difficult to disentangle the different linguistic factors that play a role in children's false belief development. For example, de Villiers (2005) suggested that different types of verbs and their semantics affect the meaning of complement clauses and how they are related to false belief. A simple interaction between verbal semantics and syntax does not, however, explain why we find a difference between first and third person complements and their relation to false belief. Our cross-linguistic research on the use and interpretation of complement clause constructions in English, German, and Chinese suggests that the meaning of the verbs and hence the meaning of the whole construction is shaped by usage patterns, which differ across languages. Such a finding is, of course, not surprising and lends further support to linguistic theories that see syntax and semantics as emerging from language use.

\section{References}

Astington, J. W., \& Jenkins, J. M. (1999). A longitudinal study of the relation between language and theory-of-mind development. Developmental Psychology, 35(5), 1311-1320.

Bannard, C., Lieven, E., \& Tomasello, M. (2009). Modeling children's early grammatical knowledge. PNAS, 106, 17284-17289. 
Boeg Thomsen, D., Theakston, A., Kandemirci, B., \& Brandt, S. (in prep.). Complements and false belief: A longitudinal study with 2- to 3-year-olds.

Brandt, S., \& Buttelmann, D. (2015, September). Theory of Mind and Complex Syntax. Paper presented at the Developmental Section and Social Section Annual Conference of the British Psychological Society, Manchester, UK.

Brandt, S., Buttelmann, D., Lieven, E., \& Tomasello, M. (2016). Children's understanding of first and third person perspectives in complement clauses and false belief tasks. Journal of Experimental Child Psychology, 151, 131-143.

Brandt, S., Lieven, E., \& Tomasello, M. (2010). Development of word order in German complement-clause constructions: Effects of input frequencies, lexical items, and discourse function. Language, 86, 583-610.

Brandt, S., Li, H., Chan, A. (submitted) What makes a complement false? Looking at the effects of verbal semantics and perspective in Mandarin children's interpretation of complement clauses and their false-belief understanding. Applied Psycholinguistics.

Carlson, S. M., Moses, L. J., \& Breton, C. (2002). How specific is the relation between executive function and theory of mind? Contributions of inhibitory control and working memory. Infant and Child Development, 11, 73-92.

Cheung, H., Husan-Chih, C., Creed, N., Ng, L., Wang, S., \& Mo, L. (2004). Relative roles of general and complementation language in theory of mind development: Evidence from Cantonese and English. Child Development, 75, 1155-1170.

Cheung, H., Chen, H., \& Yeung, W. (2009). Relations between mental verb and false belief understanding in Cantonese-speaking children. Journal of Experimental Child Psychology, 104, 141-155.

Davis, H. L. and Pratt, C. (1995), The development of children's theory of mind: The working memory explanation. Australian Journal of Psychology, 47, 25-31.

de Villiers J. (2007). The Interface of Language and Theory of Mind. Lingua, 117, $1858-1878$

de Villiers, J. G., \& Pyers, J. E. (2002). Complements to cognition: A longitudinal study of the relationship between complex syntax and false-beliefunderstanding. Cognitive Development, 17(1), 1037-1060.

Diessel, H. (2004). The Acquisition of Complex Sentences. Cambridge: Cambridge University Press.

Farrar, M.J., Benigno, J.P., Tompkins, V., \& Gage, N.A. (2017). Are there different pathways to explicit false belief understanding? General language and complementation in typical and atypical children. Cognitive Development, 43, 49-66.

Farrar, M.J., \& Maag, L. (2002). Early language development and the emergence of a theory of mind. First Language, 22, 197-213.

Harris, P. L., de Rosnay, M., \& Pons, F. (2005). Language and children's understanding of mental states. Current Directions in Psychological Science, 14(2), 69-73.

Howard Gola, A. A. (2012). Mental verb input for promoting children's theory of mind: A training study. Cognitive Development, 27, 64-76.

Lewis, S., Hacquard, V., \& Lidz, J. (2017). “Think” pragmatically: Children's interpretation of belief reports. Language Learning and Development, 13(4), 395-417.

Lohmann, H., \& Tomasello, M. (2003). The Role of Language in the Development of False Belief Understanding: A Training Study. Child Development, 74, 1130- 
1144.

MacWhinney, B. (2000). The CHILDES-project: Tools for analyzing talk. Mahwah, NJ: Lawrence Erlbaum.

Milligan, K., Astington, J. W., \& Dack, L. A. (2007). Language and theory of mind: Meta-analysis of the relation between language ability and false-belief understanding. Child Development, 78, 622-646.

Moore, C., Bryant, D., \& Furrow, D. (1989). Mental Terms and the Development of Certainty. Child Development, 60, 167-171.

Perner, J., Sprung, M., Zauner, P., \& Haider, H. (2003). Want that is understood well before say that, think that, and false belief: A test of de Villiers' linguistic determinism on German-speaking children. Child Development, 74, 179-188.

Perner, J., Stummer, S., Sprung, M., \& Doherty, M. (2002). Theory of mind finds its Piagetian perspective: Why alternative naming comes with understanding belief. Cognitive Development, 17, 1451-1472.

Pyers, J. E., \& Senghas, A. (2009). Language promotes false-belief understanding: evidence from learners of a new sign language. Psychological Science, 20(7), 805-12.

Ruffman, T., Slade, L., \& Crowe, E. (2002). The relation between children's and mothers' mental state language and theory-of-mind understanding. Child Development, 73, 734-751.

Schick, B., De Villiers, P., De Villiers, J., \& Hoffmeister, R. (2007). Language and theory of mind: a study of deaf children. Child Development, 78 (2), 376-396.

Senghas, A., \& Coppola, M. (2001). Children Creating Language: How Nicaraguan Sign Language Acquired a Spatial Grammar. Psychological Science, 12, 323328.

Tardif, T., So, C., \& Kaciroti, N. (2007). Language and false belief: Evidence for general, not specific effects in Cantonese-speaking preschoolers. Developmental Psychology, 43, 318-340.

Tardif, T., \& Wellman, H. M. (2000). Acquisition of mental state language in Mandarin- and Cantonese-speaking children. Developmental Psychology, $36(1), 25-43$.

Theakston, A. \& Lieven, E. (2017). Multiunit sequences in first language acquisition. Topics in Cognitive Science, 9, 588-603.

Thompson, Sandra A. 2002. "Object complements" and Conversation: Towards a Realistic Account. Studies in Language, 26, 125-164.

Verhagen, A. (2005). Constructions of Intersubjectivity. Discourse, Syntax and Cognition. Oxford: Oxford University Press.

Wellman, H. M., Cross, D., \& Watson, J. (2001). Meta-Analysis of Theory of Mind development: the Truth about false Belief. Child Development, 72, 655-684.

Wimmer, H., \& Perner, J. (1983). Beliefs about beliefs: representation and constraining function of wrong beliefs in young children's understanding of deception. Cognition, 13, 103-128. 